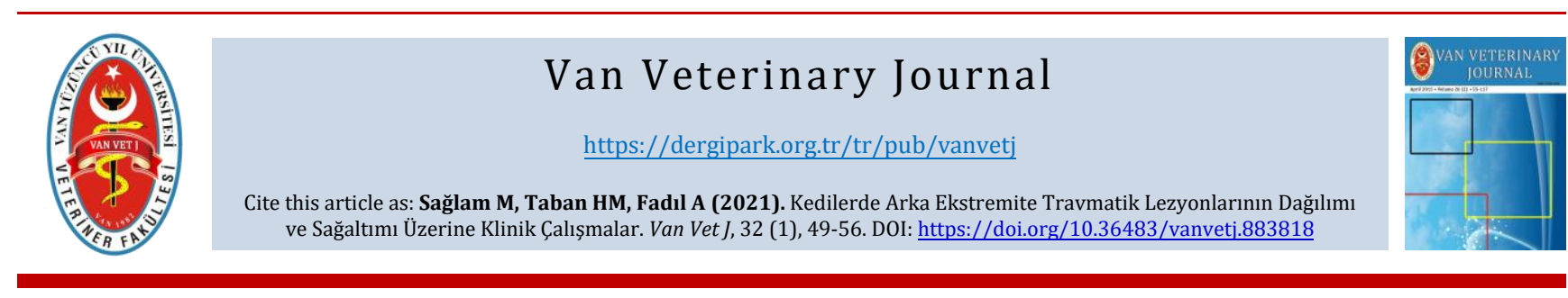

\title{
Clinical Studies on the Distribution and Treatment of Hind Limb Traumatic Lesions in Cats
}

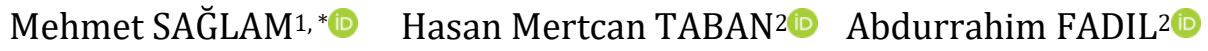 \\ ${ }^{1}$ Aksaray University, Faculty of Veterinary Medicine, Department of Surgery, Aksaray, Turkey. \\ ${ }^{2}$ Ankara University, Health Sciences Institute, Ankara, Turkey.
}

Received: 20.02 .2021

Accepted: 08.03.2021

\begin{abstract}
In this study, 20 cats of different breeds, ages and genders with traumatic lesions in the hind limbs that were brought to the Clinic of Surgery, Animal Hospital Faculty of Veterinary Medicine, Ankara University were evaluated. Clinical examination and radiological examination were performed in the bones of the hind limbs. According to these findings, fractures in 13 cases, coxal joint luxation in 2 cases, tarsal joint luxation in 2 cases and open wound in 3 cases were detected and necessary post-operative controls were maintained. Systemic examinations of the cases were performed according to the anamnesis and inspection findings. The related extremity was examined for pain, temperature, swelling, deformity, abnormal movement, crepitation and asymmetry. Using support bandages or restriction of the area were sufficient in non-displaced fractures. Maintenance and control procedures were routinely performed in patients undergoing conservative treatment as well. Successful results were obtained in the treatment of lesions requiring open reduction and fixation. In conclusion, general description, causes and localization of the traumatic lesions in the hind limbs of cats and the indicated treatment of the clinical cases and along with their results, as well as detailed information about the treatment methods were presented in this study. Besides, postoperative complications were also reported. As a result, it is believed that this study will provide a guiding contribution to clinical

Keywords: Cat, ekstremity, trauma, treatment
\end{abstract}

öz

\section{Kedilerde Arka Ekstremite Travmatik Lezyonlarının Dağılımı ve Sağaltımı Üzerine Klinik Çalışmalar}

Bu çalışmada, Ankara Üniversitesi Veteriner Fakültesi Hayvan Hastanesi Cerrahi Kliniğine getirilen, arka ekstremitelerinde travmatik lezyonlar bulunan farklı ırk, yaș ve cinsiyetteki 20 kedi değerlendirildi. Olgularda gerçekleștirilen klinik ve radyolojik muayeneler sonrasında; 13 olguda arka ekstremiteleri kemiklerinde kırık, 2 olguda caput femoris lüksasyonu, 2 olgu'da art. tarsi lüksasyonu, 3 olgu'da açık yara şekillenmiş olup, endike olan sağaltımları gerçekleștirilerek postoperatif kontroller sürdürülmüștür. Olguların anamnezleri ve inspeksiyon bulgularına göre sistemik muayeneleri gerçekleştirildi. Lezyon belirlenen ekstremite ağrı, sıcaklık, șişkinlik, deformite, anormal hareket, krepitasyon ve diğer ekstremitesi ile asimetri bulguları yönünden muayene edildi. Konservatif sağaltım endikasyonu bulunan kırıklarda destekli bandaj ve kısıtlı alan uygulamaları yeterli olup, rutin bakım ve kontrolleri sürdürüldü. Açık redüksiyon ve fiksasyon gerektiren olgularda endike olan sağaltım yöntemleri ve postoperatif rutin kontrolleri sürdürülerek fonksiyonel iyileşmeleri sağlandı. Klinik olguların değerlendirildiği bu çalışmada, kedilerde karşılaşılan arka ekstremite travmatik lezyonlarının genel olarak tanımı, oluşum nedenleri, lokalizasyonu ile endike olan konservatif veya operatif sağaltım yöntemlerinin uygulanmasına ilişkin ayrıntılı bilgiler aktarılmıştır.

Anahtar Kelimeler: Ekstremite, kedi, sağaltım, travma

\section{Giriș}

Travmatik etkenler bir hayvanda birtakım değişiklikler, yaralanma ya da ölüm oluşturabilecek bulunduğu çevre kaynaklı herhangi bir etki ya da kuvvet olarak tanımlanmaktadır. Geniş anlamda; gelecekte ortaya çıkabilen bir hastalık için zemin yaratan, stres oluşturan ya da fonksiyon bozukluklarına sebep olabilecek indirekt çevresel faktörler (örneğin, fiziksel, kimyasal faktörler) olarak tanımlanır (Kolata 1980; Selcer ve ark. 1987).

Travma yaratan direkt etkili birçok faktör bildirilmiştir. Bu faktörler ayrı ayrı değerlendirildiği gibi, birçoğunun beraber incelendiği bilimsel çalışmalar da yapılmıştır. 
Travmatik bir lezyon olușturan en önemlisi de trafik kazalarıdır. Sonra sırasıyla bilinmeyen nedenler, hayvanların birbirleriyle olan kavgaları ve diğer faktörler gelir (Kolata ve Johnston 1975; Schebitz ve ark. 1983; Swaim 1985).

Kolata ve ark. (1974)'na göre travmatik etkenler; trafik kazaları, hayvanların birbiriyle olan kavgaları, kesici ya da sivri cisim yaralanmaları, ateşli silah ile yaralanmalar, yanıklar, ezilmeler, düşmeler, insanların sebep olduğu lezyonlar ve bilinmeyen nedenler olarak 9 gruba ayrılır. Daha az oranda karşılaşılan direkt etkenler ise; farklı patlayıcıların sebep olduğu travma, donma, güneş çarpması, boğulma, elektriksel etkenler ve lineer ya da non-lineer gastro-intestinal yabancı cisimler etkileridir. Diğer önemli direkt travmatik etkenler ise; endüstriyel, tarımsal, ev ve bahçede günlük kullanılan kimyasal maddelerle hayvanların temas durumudur.

Cinsiyetin de travma için bir risk faktörü olduğu tanımlanmaktadır. Erkeklerin dișilere göre daha gezgin olmalarıyla, kavga riskinin bulunmasiyla travmatik etkilenmelerinin daha çok olduğu belirtilmektedir. Dişilerin çoğunlukla ev ortamında kalmasıyla; düşme, ezik ve yanık gibi vakalar gözlenir. Yaş faktörü olarak, gençlerin yaşlılara göre daha aktif olmalarıyla travma ile karşılaşma ihtimallerinin fazla olduğu vurgulanmıştır (Kolata ve ark. 1974).

Kedilerde ekstremitelerin farklı travmatik lezyonlarına rastlanmaktadır (Slatter 2003). Bu travmatik lezyonlar içinde en sık kırık oluşumlarıyla karşılaşılır. Yumuşak dokular için genellikle ezilme, kesik yarası, sivri ve batıcı cisim yaraları, ısırık ve ateşli silah yaraları, yanık oluşu, yalama ile oluşan granülomlar diğer karşılaşılan lezyonlardır. Çoğunlukla art. coxae'da olmak üzere diğer eklemlerde oluşan travmatik luksasyonlar, LCA (lig. cruciatum anterius) rupturu, derin ya da perfore eklem yaralanmaları da karşılaşılan diğer travmatik lezyonlardır (Kolata ve ark. 1974).

Yapılan bir çalışmada, travmatik lezyonların dağılımı; kırık olușumu \%49, değișik yaralar \%17, çıkıklar \%7, medulla spinalis ve perifer sinir lezyon oluşumları \%6, kontüzyonlar $\% 5$, otitis externa $\% 3$, fistül $\% 2$, ateșli silah yaralanması \%1, LCA rupturu \%0,7 olarak belirlenmiștir. Ayrıca, kedilerde karşılaşılan travmatik lezyonların risk faktörünün, öncelikle bu kedilerin insan denetiminde olmaması, yaş ve cinsiyet olduğu belirlenmiştir (Kolata 1980).

Travmatik kırıklar, etkileyen kuvvetin şiddeti ve bunları absorbe edebilme gücüne göre; küçük bir çatlak, bir ya da birden fazla kemikte kırık oluşumu, bunlara komşu eklemlerde çıkık oluşumuna (kırıklı çıkık) kadar değişikgenlik gösterebilir. Kırık oluşturan kuvvet; sadece kemikte kırık oluşturmayıp, kemik çevresindeki deri, kas, damar, tendo, ligament, sinir ve komşu doku ve organları da yaralayabilir (Kenneth ve Joceph 2004; Us 2004).

Arka ekstremite kemiklerindeki kırıkların sağaltımında; genellikle bandaj uygulamaları, konservatif sağaltım, internal ve eksternal fiksatör uygulamalarıyla redüksiyon ve fiksasyon gerçekleştirilir (Scott ve Mc Laughlın 2007).

Eklemin destek yapılarının değişik lezyonları sonucunda luksasyon şekillenebilir ve ilgili ekstremitede fonksiyonel bozukluğa sebep olur. Ligamentler eklemin primer destekleri olup, eklem kapsülü, tendolar ve kaslar da sekonder destekler olarak katkı sağlarlar. Luksasyon oluşan eklemde, eklemin normal lubrikasyonu ve eklem kıkırdağın fizyolojik beslenmesi bozulur. Ayrıca, luksasyon nedeniyle karşılıklı olmayan eklem yüzeylerine binen ağırlık, eklem kıkırdağında da lezyon olușturur (Harrari ve ark. 1996; Aslanbey 2002).

LCA rupturu yalnız köpek ve kediler için değil, insanlar için de çok sık görülen bir lezyondur (Piermettei ve Flo 1997). Aniden olan internal rotasyon, trafik kazaları, kediler koşarken bir anda alçak zemine düşmeleri, LCA vasküler bozukluğu, fossa intercondylaris'in anatomik yönden dar yapıda oluşu, vücut ağırlı̆̆ının fazla oluşu, kedinin aşırı hareketliliği, operasyonlar, arka ekstremitenin duruş bozukluğu ve fiziksel kondüsyon bozuklukları nedenler arasındadır (Piermettei ve Flo 1997; Slatter 2003). İnspeksiyon, oturma testi, öne çekmece ve arkaya çekmece hareket testleri, tibial kompresyon testi, genu varum ve genu valgus stres testi, radyolojik yönden çeşitli test ve muayeneler ile tanı gerçekleștirilir (Slatter 2003). LCA rupturunun sağaltımındaki operatif yöntemlerin farklılığına rağmen, temel prensip olan eklem stabilitesini yeniden sağlamak düşüncesi değişmemektedir (Sağlam ve Kaya 2000).

Veteriner cerrahide oldukça fazla karşılaşılan travmatik lezyonların; kedilerde arka ekstremitelerinde şekillenen lezyonların dağılımı, bunları oluşumunda belirlenen farklı travmatik etkiler ve oluşan lezyonların endike olan sağaltım seçenekleri ile sonuçlarının aktarılması ile bu konuda çalışan veteriner hekim klinisyenler için yönlendirici olması ve benzer çalışmalarda katkı sağlaması amaçlanmıştır.

\section{MATERYAL ve METOT}

Araştırmanın gereç ve yöntemi Ankara Üniversitesi Deney Hayvanları Yerel Etik Kurulu tarafindan onaylanmıştır (Karar No: 2019-4-40, Tarih: 06.02.2019).

Çalışma materyalini Ankara Üniversitesi Veteriner Fakültesi Hayvan Hastanesi Cerrahi Kliniği'ne arka ekstremite travması nedeniyle getirilen, değișik yaş (4 ay3 yaş), ırk ve cinsiyetteki 20 kedi oluşturmuştur.

Yapılan klinik ve radyolojik muayeneler sonucunda, 13 olguda arka ekstremite kemiklerinde kırık, 2 olguda caput femoris'de luksasyon, 2 olguda art. tarsi'de luksasyon, 3 olguda açık yara belirlenmiştir. Travmatik lezyonların sağaltımları konservatif veya endike olan operatif yöntemlerle gerçekleştirilmiş, postoperatif kontrolleri sürdürülmüștür. Olgulara ait klinik bilgiler Tablo 1'de sunulmuştur.

Klinik ve radyolojik muayeneler için gerektiğinde medetomidine HCI (Domitor, Voetis) ve xylazine $\mathrm{HCl} \% 2$ (Rompun ${ }^{\circledR}$ 23,32 mg/ml, Bayer) ile yeterli sedasyon sağlanmıştır. Operatif sağaltım endikasyonu bulunan olgular için, xylazin $\mathrm{HCl} \% 2$ (Rompun ${ }^{\circledR} 23,32 \mathrm{mg} / \mathrm{ml}$, Bayer) $0,1 \mathrm{ml} / \mathrm{kg}$ dozunda intramuskuler uygulanmasıyla sağlanan premedikasyon sonrasında, ketamin $\mathrm{HCl} \% 10$ (Ketasol@ $100 \mathrm{mg} / \mathrm{ml}$, Richterpharma) 0,1 ml/kg dozunda intramuskuler uygulanarak genel anestezi sağlandı. Operasyon bölgesi kapatıldıktan sonra, lokal antibiyotik olarak 3-5 mg/kg dozunda rifamycin (Rifosin ${ }^{\circledR} 250$ $\mathrm{mg} / \mathrm{ml}$, Avebtis) uygulandı. Daha sonra bölge bandaj uygulamasıyla korundu. Gerektiğinde Elizabeth yakalık kullanıldı. Postoperatif analjezi sağlamak amacıyla meloksikam (Metacam 0,5mg/ml, Boehringer-İngelheim) kullanılmıştır.

Sağaltım amaçlı şirurjikal girişimlerde rutin olan operasyon setleri kullanıldı. Kırık oluşumlarının sağaltımında değişik çaplarda Kirschner ve Steinmann pinleri, lag vidası ile $0.8^{\prime}$ lik serklaj teli kullanılmıştır. 
Tablo 1. Olgularda ırk, yaş, cinsiyet, lezyonu oluşturan neden, lezyonun yeri ve uygulanan sağaltıma göre dağılım.

Table 1. Distribution of cases according to breed, age, sex, cause of the lesion, location of the lesion and treatment applied.

\begin{tabular}{|c|c|c|c|c|c|c|}
\hline $\begin{array}{c}\text { Olgu } \\
\text { no }\end{array}$ & Irk & $\begin{array}{l}\text { Yaş } \\
\text { (Ay) }\end{array}$ & Cinsiyet & $\begin{array}{c}\text { Travmatik } \\
\text { neden }\end{array}$ & $\begin{array}{c}\text { Oluşan lezyon ve } \\
\text { lokalizasyonu }\end{array}$ & $\begin{array}{l}\text { Uygulanan } \\
\text { sağaltım }\end{array}$ \\
\hline 1 & Melez & 4 & Erkek & Küt Travma & Sağ collum femoris kırığı & Eksizyon artroplastisi \\
\hline 2 & Melez & 8 & Dişi & Sıkışma & $\begin{array}{l}\text { Sağ caput femoris } \\
\text { luksasyonu }\end{array}$ & Eksizyon artroplastisi \\
\hline 3 & Melez & 12 & Erkek & Bilinmiyor & $\begin{array}{l}\text { Sağ femur'da diyafizer } \\
\text { parçalı kırık }\end{array}$ & $\begin{array}{l}\text { İM pin ve serklaj teli uygulaması ile } \\
\text { osteosentez }\end{array}$ \\
\hline 4 & Melez & 12 & Dişi & Küt travma & $\begin{array}{l}\text { Sağ femur'da diyafizer } \\
\text { parçalı kırık }\end{array}$ & $\begin{array}{l}\text { İM pin ve serklaj teli uygulaması ile } \\
\text { osteosentez }\end{array}$ \\
\hline 5 & Melez & 12 & Dişi & Trafik kazası & Sol femur'da epifizer kırık & $\begin{array}{l}\text { Armstead-lumb ve çapraz pin yöntemi } \\
\text { ile osteosentez }\end{array}$ \\
\hline 6 & Tekir & 9 & Erkek & $\begin{array}{l}\text { Yüksekten } \\
\text { düşme }\end{array}$ & Sol femur'da epifizer kırık & Çapraz pin yöntemi ile osteosentez \\
\hline 7 & Tekir & 8 & Dişi & Küt travma & $\begin{array}{l}\text { Sol caput femoris'de } \\
\text { avülsiyon ve trochanter } \\
\text { major kırığ }\end{array}$ & $\begin{array}{l}\text { Kirshner pini ve germe teli uygulaması } \\
\text { ile osteosentez }\end{array}$ \\
\hline 8 & Melez & 10 & Dişi & $\begin{array}{l}\text { Yüksekten } \\
\text { düșme }\end{array}$ & $\begin{array}{l}\text { Sağ femur'da } \\
\text { suprakondiler kırık }\end{array}$ & $\begin{array}{l}\text { Çapraz rush pini ve çapraz Kirschner } \\
\text { teli uygulaması ile osteosentez }\end{array}$ \\
\hline 9 & Siyam & 24 & Erkek & $\begin{array}{l}\text { Yüksekten } \\
\text { düșme }\end{array}$ & $\begin{array}{l}\text { Sağ ve sol tarsal } \\
\text { kemiklerde kırık }\end{array}$ & İM pin uygulaması ile osteosentez \\
\hline 10 & Van & 18 & Diși & Bilinmiyor & $\begin{array}{l}\text { Sol tibia'da diyafizer } \\
\text { parçalı kırığı }\end{array}$ & $\begin{array}{l}\text { İM pin ve serklaj teli uygulaması ile } \\
\text { osteosentez }\end{array}$ \\
\hline 11 & Ankara & 7 & Diși & $\begin{array}{l}\text { Yüksekten } \\
\text { düșme }\end{array}$ & $\begin{array}{l}\text { Sol femur'da suprakondiler } \\
\text { ve intrakondiler kırık }\end{array}$ & $\begin{array}{l}\text { İnterkondiler lag vidası ve çapraz pin } \\
\text { ile osteosentez }\end{array}$ \\
\hline 12 & Melez & 9 & Erkek & Küt travma & $\begin{array}{l}\text { Sol tibia ve fibula'da } \\
\text { diyafizer kırık }\end{array}$ & İM pin uygulaması ile osteosentez \\
\hline 13 & Ankara & 36 & Diși & $\begin{array}{l}\text { Yüksekten } \\
\text { düșme }\end{array}$ & Sol art. tarsi luksasyonu & Bandaj uygulaması \\
\hline 14 & Melez & 9 & Erkek & Bilinmiyor & Sağ tibia'da açık yara & Açık yara sağaltımı \\
\hline 15 & Melez & 12 & Erkek & Küt travma & $\begin{array}{l}\text { Sağ femur'da diyafizer } \\
\text { parçalı kırık }\end{array}$ & $\begin{array}{l}\text { İM pin ve serklaj teli uygulaması ile } \\
\text { osteosentez }\end{array}$ \\
\hline 16 & Melez & 8 & Erkek & Küt travma & Sağ art. tarsi luksasyonu & Bandaj uygulaması \\
\hline 17 & Melez & 24 & Dişi & $\begin{array}{l}\text { Yüksekten } \\
\text { düșme }\end{array}$ & $\begin{array}{l}\text { Sağ tibia'da diyafizer açık } \\
\text { kırık }\end{array}$ & İM pin uygulaması ile osteosentez \\
\hline 18 & Melez & 12 & Dişi & Bilinmiyor & Sol tibia'da açık yara & Açık yara sağaltımı \\
\hline 19 & Tekir & 12 & Erkek & Bilinmiyor & $\begin{array}{l}\text { Sol caput femoris } \\
\text { luksasyonu }\end{array}$ & Bandaj uygulaması \\
\hline 20 & Melez & 12 & Diși & $\begin{array}{l}\text { Sivri cisimle } \\
\text { kesik }\end{array}$ & Sol tarsal bölgede açık yara & Açık yara sağaltımı \\
\hline
\end{tabular}

Arka ekstremitelerin travmatik lezyonları şikâyeti ile getirilen olguların anamnezleri ve inspeksiyon bulgularına göre klinik muayeneleri yapıldı. Lezyon belirlenen ekstremite deformasyon, şişkinlik, sıcaklık, ağrı, anormal hareket, krepitasyon ve karşıtı ekstremite ile asimetri belirtileri yönünden muayene edildi. Klinik muayenelerden sonrası gerekli olan olgularda özel pozisyonlarda radyografileri alınarak klinik tanı kesinleştirildi.

\section{Sağaltım}

Belirlenen lezyonlar için endike olan operatif sağaltımlar, olguların sağlanan sedasyon ve genel anestezileri sonrası, operasyon masasına alınmasıyla ilgili bölgenin operatif sağaltımı için rutin hazırlığı yapıldı. Konservatif sağaltım endikasyonu bulunan olgularda gerekli olan destekli bandaj uygulaması 15. günde uzaklaştırılarak, klasik kafes uygulaması 2 hafta daha sürdürülmüștür. Daha sonra klinik ve radyolojik kontrolleri yapılmıștır.

\section{Caput Femoris Luksasyonunda Kapalı Redüksiyon}

Kalça ekleminin kapalı redüksiyonu için olgu no 19 genel anestezi altında ilgili ekstremite üste gelecek şekilde lateral pozisyonda operasyon masasına alındı. Bir el genu eklemini fleksiyonda medialden tesbit edecek şekilde, diğer elle trochanter major üzerinde basınç uygulamasıyla caput femoris acetabulum üzerine getirildi. Caput femoris acetabular kenar üzerinden kaydırıldığında, redüksiyonu gerçekleştirmek amacıyla ekstremitenin medial rotasyonu birlikte gerçekleștirilerek redüksiyon sağlandı. Alınan radyografi ile redüksiyon doğrulandı. Genu eklemi fleksiyonda iken trochanter major üzerinden basınç yaratacak șekilde yapılan bandaj uygulaması 14. günde uzaklaștırıldı.

\section{Eksizyon Artroplastisi}

Caput femoris luksasyonu belirlenen 2 olguda (olgu no 1 ve 2) (Şekil 1) eksizyon artroplastisi gerçekleștirildi. Genel anestezi altında kalça eklemine craniolateral yaklaşım uygulandı. Trochanter major medial yüzünden başlayarak ve trochanter tertius proksimal yüzüne kadar osteotomi 
(osteotomi hattı transversal eksene dik olarak) gerçekleştirildi. Collum femoris bölgeden uzaklaştırıldı. Operasyon sonrası ilgili ekstremitede uygulanan bandaj, deri dikişlerinin 12. günde alınmasıyla uzaklaştırıldı.

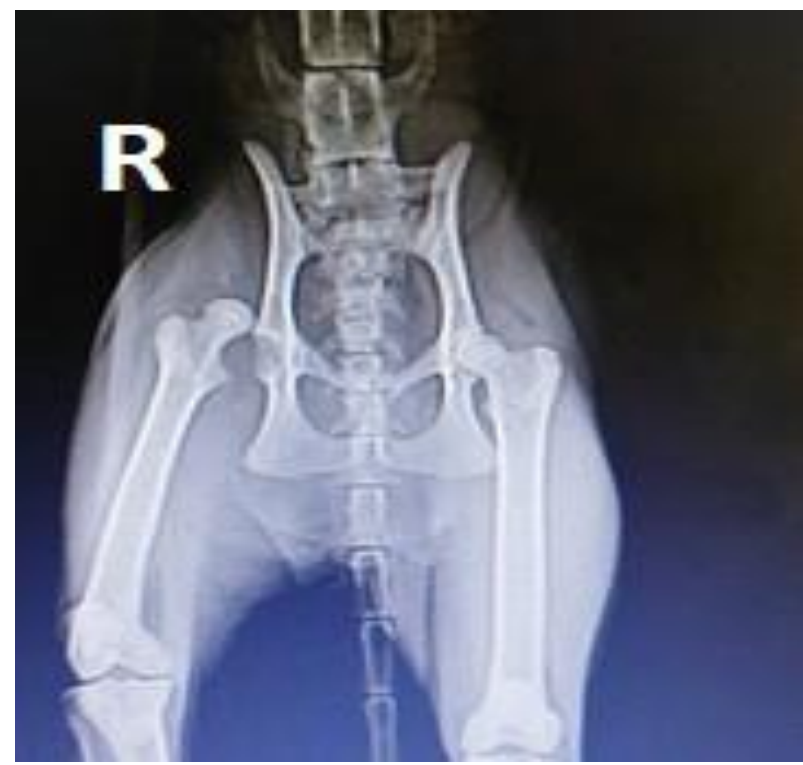

Şekil 1. Olgu no 2'de sağ caput femoris'te oluşan luksasyonun $\mathrm{V} / \mathrm{D}$ radyografisi.

Figure 1. Case $2 \mathrm{~V} / \mathrm{D}$ radiography of luxation in the right caput femoris.

\section{Femur Kırıkları}

Collum femoris ve trochanter major kırığı olan bir olguda (olgu no 7) Kirshner pini ve germe teli ile osteosentez gerçekleștirildi (Șekil 2). Bölge rutin uygulama ile kapatıldı. Operasyon sonrası uygulanan destekli bandaj, 10. günde deri dikişlerinin alınmasıyla tekrarlanarak 3 . hafta sonunda uzaklaştırıldı.
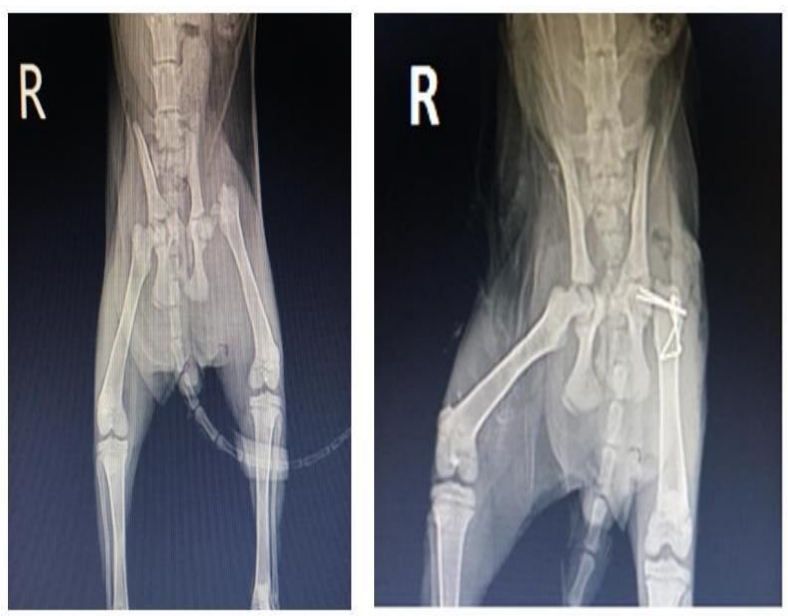

Şekil 2. Olgu no 7'de sol caput femoris avülsiyon ve trochanter major kırığı ve postoperatif Kirshner teli ve germe teli uygulamasının A/P radyografileri.

Figure 2. Case $7 \mathrm{~A} / \mathrm{P}$ radiography of left caput femoris avulsion and trochanter major fracture and Postoperative $\mathrm{A} / \mathrm{P}$ radiography of Kirshner and tension wire combination application.

Femur'da diyafizer parçalı kırık belirlenen 3 olguda (olgu no $3,4,15$ ) açık redüksiyon sonrası intramedullar pin ve serklaj telleri uygulamasıyla fiksasyon sağlandı (Şekil 3). Uygulanan pinin ekleme penetrasyonu yönünden kontrol edildi. Bölge rutin yöntemlerle kapatıldıktan sonra uygulanan destekli bandaj, 10. günde deri dikişlerinin alınmasıyla tekrarlanarak 3. hafta sonunda uzaklaștırıldı.

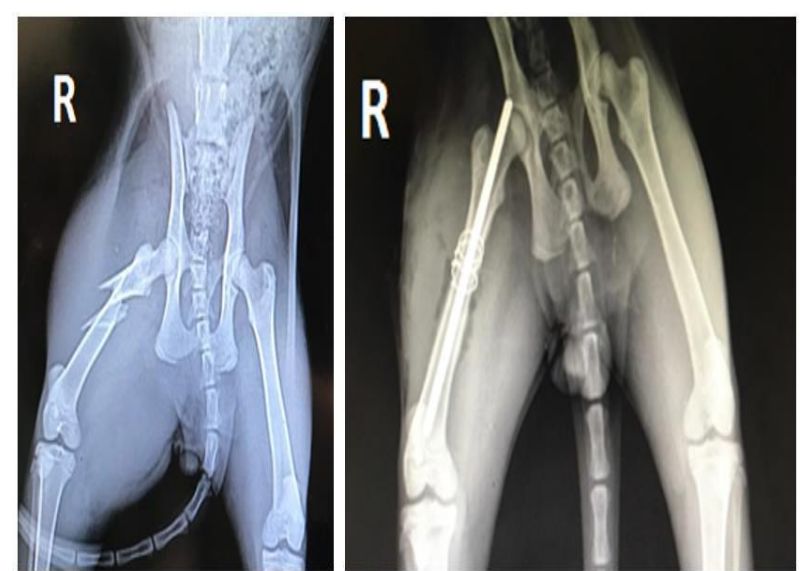

Şekil 3. Olgu no 4'de sağ femurda oluşan diyafizer parçalı kırık ve postoperatif İM pin ve serklaj teli uygulamasının A/P radyografileri.

Figure 3. Case $4 \mathrm{~A} / \mathrm{P}$ radiography of the diaphyseal fragment fracture of the right femur and Postoperative $\mathrm{A} / \mathrm{P}$ radiography of IM pin and cerclage wire combination application.

Femur'da epifizer kırık belirlenen olgu no 5'de ArmsteadLumb ve çapraz pin yöntemi ile redüksiyon sonrasında fiksasyon sağlandı (Şekil 4).

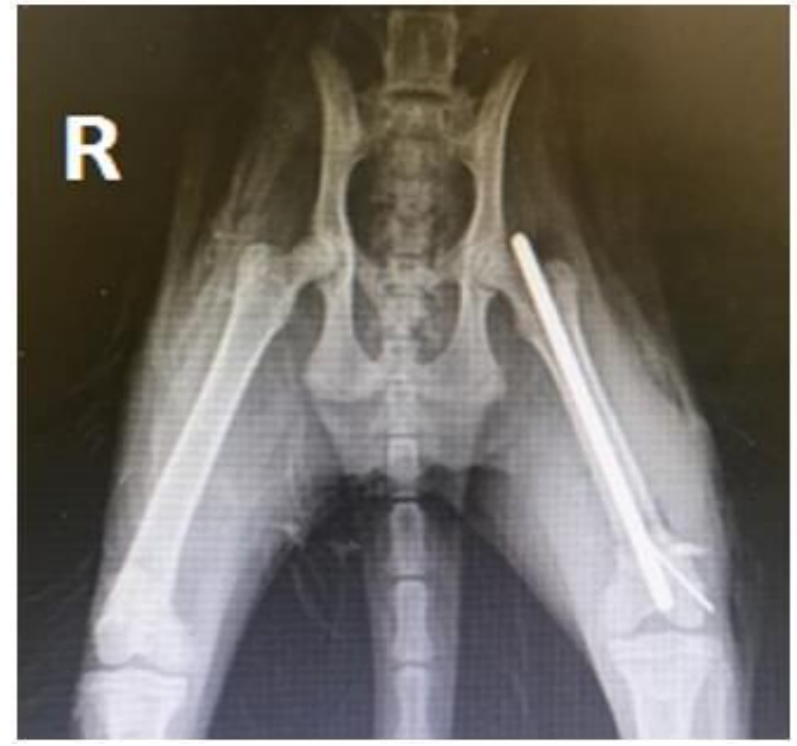

Şekil 4. Olgu no 5'in Armstead-Lumb ve çapraz pin ile fiksasyonu gerçekleştirilen epifizer femur kırığının postoperatif A/P radyografisi.

Figure 4. Case 5 Postoperative $\mathrm{A} / \mathrm{P}$ radiography of the epiphyseal femur fracture fixed by Armstead-Lumb and cross pin combination.

Suprakondiler femur kırığı belirlenen olgu no 8'de çapraz rush pini ve çapraz Kirschner teli uygulamasıyla kırığın fiksasyonu sağlandı. Bölge uygun yöntemlerle kapatıldıktan sonra uygulanan destekli bandaj, 10. günde deri dikişlerinin alınmasıyla tekrarlanarak 3. hafta sonunda uzaklaştırıldı.

Suprakondiler ve intrakondiler kırık belirlenen olgu no 11 'de redüksiyonu sağlamak için çapraz rush pini ve lag vidası uygulandı (Şekil 5). Bölge uygun yöntemlerle kapatıldıktan sonra uygulanan destekli bandaj, 10. günde deri dikişlerinin alınmasıyla tekrarlanarak 3. hafta sonunda uzaklaştırıldı. 


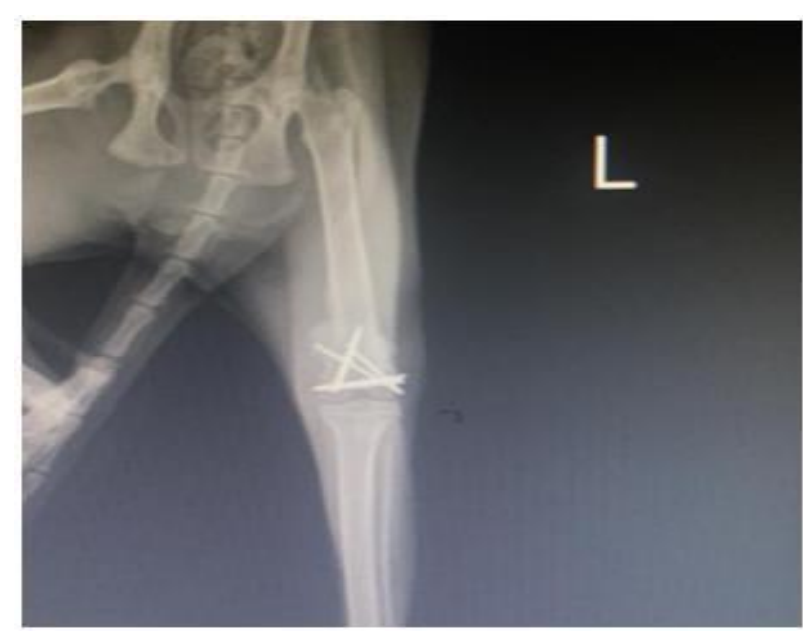

Şekil 5. Olgu no 11 'de çapraz Rush pini ve lag vidası ile gerçekleştirilen suprakondiler Y kırığının postoperatif A/P radyografisi.

Figure 5. Case 11 Postoperative A/P radiography of supracondylar Y fracture performed with crossed Rush pin and lag screw combination.

\section{Tibia Kırıkları}

Diyafizer tibia kırıklarında (olgu no $10,12,17$ ) tibia'nın medial yüzünden operatif yaklaşım gerçekleştirildi. Kırık uçlarında gereken düzeltmeler yapıldıktan sonra, retrograd yöntemle uygulanan intramedullar pin ve serklaj teli ile fiksasyon gerçekleștirildi. Bölge kapatıldıktan sonra da ilgili ekstremite 3 hafta destekli bandajla korundu.

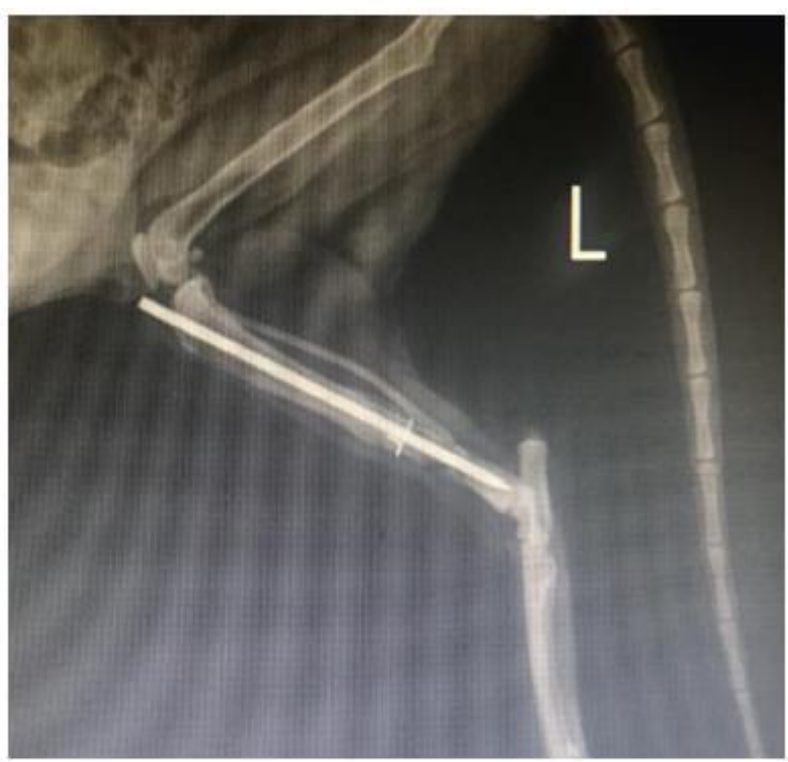

Şekil 6. Olgu no 10 'da İM pin ve serklaj teli uygulamasıyla gerçekleştirilen diyafizer tibia kırığının postoperatif M/L radyografisi.

Figure 6. Case 10 postoperative $\mathrm{M} / \mathrm{L}$ radiography of the diaphyseal tibia fracture performed with IM pin and cerclage wire combination application.

\section{Art. Tarsi Luksasyonu}

Art. tarsi luksasyonu olan iki olguda (olgu no 13, 16) dıştan koaptasyon uygulandı. Bölge 4-6 hafta boyunca destekli bandaj ile korundu. Hareket kısıtlaması önerildi.

\section{Tarsal Kırık}

Tarsal kırık belirlenen olgu no 9'da İM pinin anterograd uygulanması ile fiksasyon gerçekleștirildi (Şekil 7). Bölge kapatıldıktan sonra ilgili ekstremite 3 hafta destekli bandajla korundu. Kedinin aktivitesi kısıtlandırıldı.


Şekil 7. Olgu no 9'da sağ ve sol tarsal kemiklerdeki oluşan kırık ve postoperatif İM pin ve serklaj teli uygulaması ile gerçekleștirilen $\mathrm{A} / \mathrm{P}$ radyografileri.

Figure 7. Case $9 \mathrm{~A} / \mathrm{P}$ radiography of the fracture in the right and left tarsal bones and Postoperative A/P radiography of tarsal bone fractures performed with IM pin and cerclage.

\section{Açık Yara}

Açlk yara şekillenmiş olan 4 olguda (olgu no 14, 17, 18, 20) açık yara sağaltımı gerçekleştirildi. Bunun için kanamanın kontrolü ve olası kontaminasyonu önlemek amacıyla yapılan yara sağaltımı sonrası pansumanla korundu. İyleșmenin daha çabuk olması amacıyla yara dudakları yaklaştırılarak dikiș uygulaması yapıldı. Bölge kuru pansumanla korunarak enfeksiyon riskine karşılık 5-7 gün süreyle parenteral antibiyotik uygulandı.

\section{BULGULAR}

Olgularda Irk, Cinsiyet, Yaş ve Travma Oluşturan Nedene Göre Dağılım

Calıșmayı olușturan 20 kedide travmaya bağlı arka ekstermite lezyonlarının nedeni lokalizasyonu ile birlikte olası diğer lezyonlar ve bu lezyonların endike olan yöntemlerle sağaltımı gerçekleştirilerek, sonraki iyileşme durumları ile oluşan komplikasyonlar değerlendirildi.

Çalışma materyalini oluşturan 20 kedinin ırk dağılımında; 13 olgunun melez, 3 olgunun Tekir, 2 olgunun Ankara, 1 olgunun Siyam ve 1 olgunun da Van Kedisi olduğu saptandı (Şekil 8).

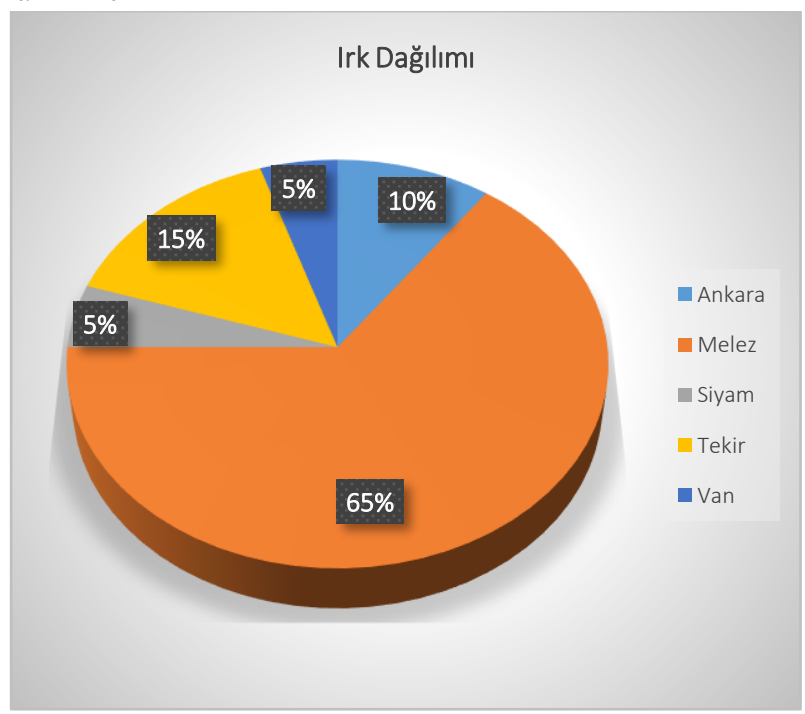

Şekil 8. Olguların ırk dağılımı.

Figure 8. Breed distribution of the cases. 
Olguların cinsiyet dağılımının ise; 9 erkek ve 11 diși kedi olduğu belirlendi (Șekil 9). Çalıșmada kullanılan kedilerin yaş dağılımının da 5 kedinin 4-8 aylık, 8 kedinin 8-12 aylık, 6 kedinin 12-24 aylık ve 1 kedinin 24-36 aylık yas aralığında olduğu belirlendi (Şekil 10). Olguların medyanı 12 aylık olarak hesaplanmıştır.

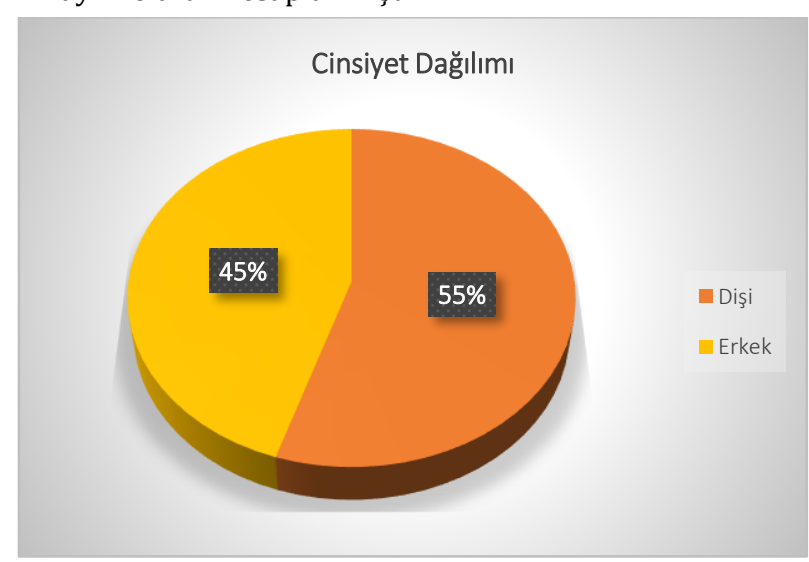

Şekil 9. Olguların cinsiyet dağılımı.

Figure 9. Gender distribution of the cases.

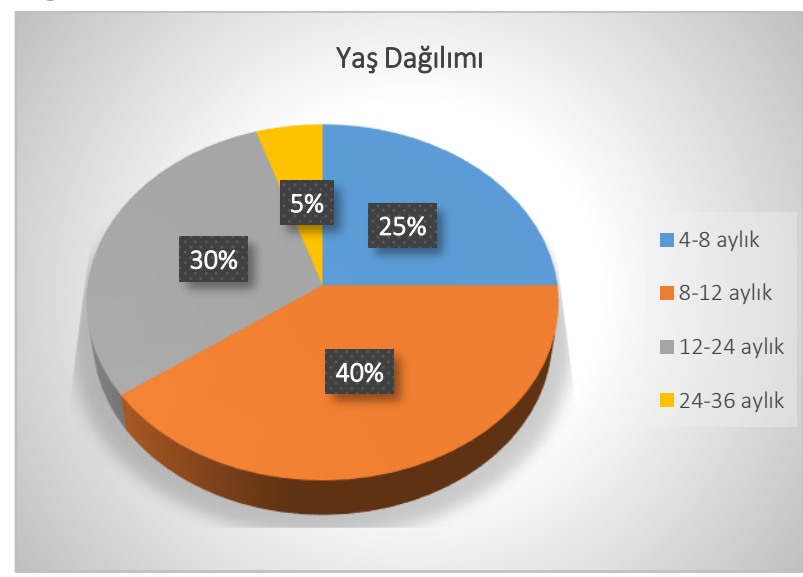

Şekil 10. Olguların yaş dağılımı.

Figure 10. Age distribution of the cases

Lezyon oluşturan travmatik nedenlerin dağılımda; 6 olgu'da yüksekten düşme (\%30), 6 olgu'da küt travma (\%30), 1 olgu'da trafik kazası (\%5), 1 olgu'da sıkışma (\%5), 1 olgu'da sivri cisimle kesik (\%5) etken olurken, 5 olgu'da (\%25) lezyonu oluşturan neden belirtilmemiştir (Şekil 11).

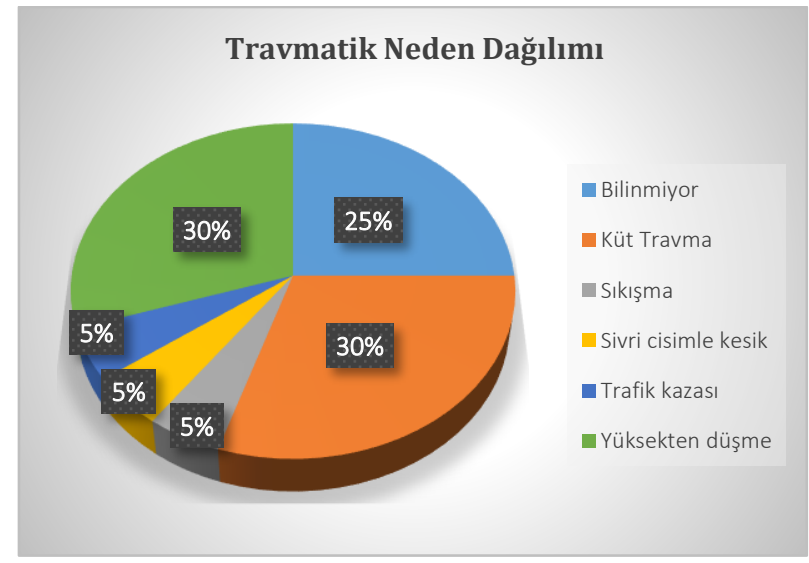

Şekil 11. Olgularda lezyon oluşturan travmatik nedenlerin dağılımı.

Figure 11. Distribution of traumatic causes causing lesions in cases.
Değișik travmatik nedenlerle arka ekstremitelerde belirlenen lezyonların çoğunluğunu kırık oluşturmuştur. Buna göre; 13 olgu'da kırık (\%65), 4 olgu'da luksasyon (\%20) ve 3 olgu'da açık yara (\%15) belirlenmiştir (Şekil 12).

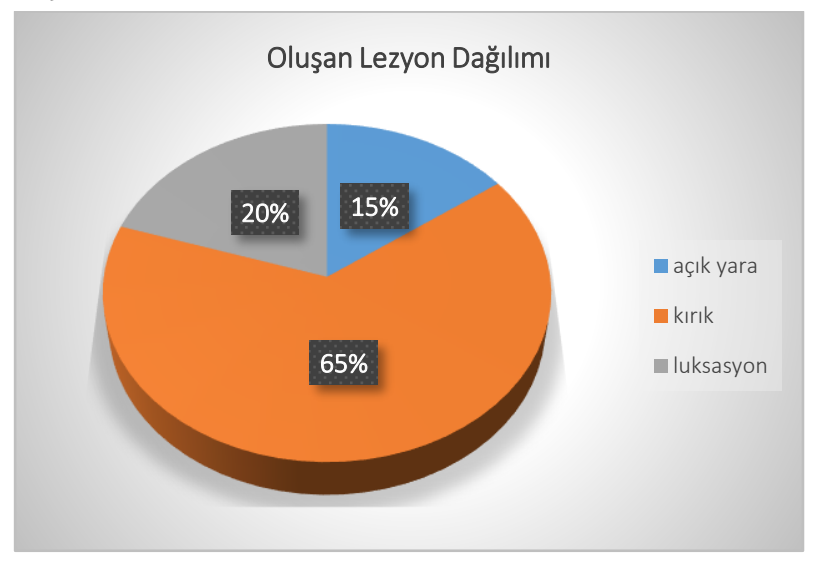

Şekil 12. Olgularda oluşan lezyonların dağılımı.

Figure 12. Distribution of lesions in the cases

Ayrıca travmatik nedene göre oluşan lezyonların dağılımı Şekil 13'de sunulmuş olup, buna göre yüksekten düşme ve küt travmalar çoğunlukla kırık ile sonuçlanırken, luksasyon oluşumununda bu travmatik nedenlere ek olarak sıkışmanın da etken olduğu belirlenmiştir.

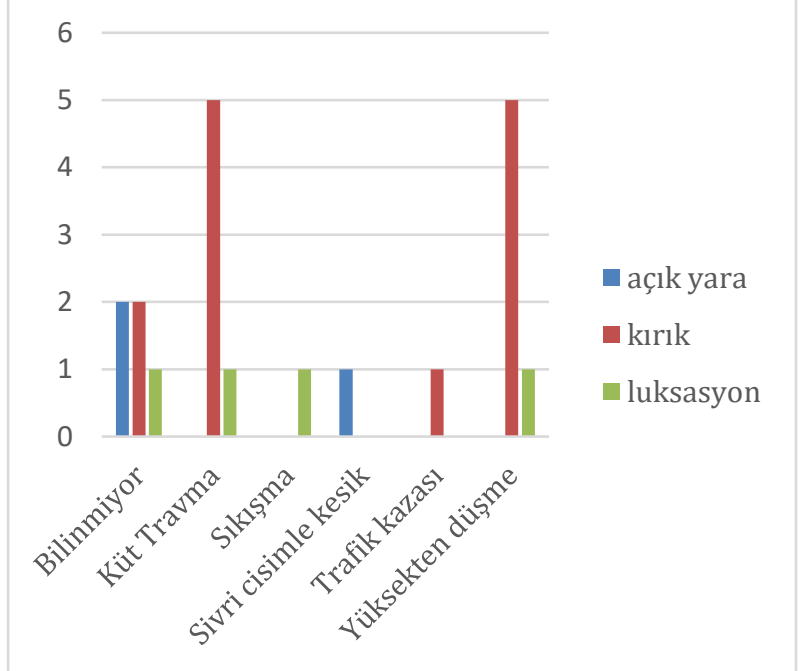

Şekil 13. Olguların travmatik nedenine göre oluşan lezyonların dağılımı.

Figure 13. Distribution of lesions according to the traumatic cause of the cases.

\section{Olguların Postoperatif Muayene Bulguları}

Postoperatif dönemde periyodik olarak olguların 2 ay süresince klinik, radyolojik kontrolleri sürdürüldü. Radyolojik kontrollerde kırık bölgelerinde açılı ya da yanlış kaynama, taşkın kallus oluşumuna ilişkin bulgular gözlenmemiştir. Caput femoris luksasyonu belirlenen olgularda eksizyon artroplasti ve kapalı redüksiyon uygulanan hastalarda herhangi bir olumsuzluk belirlenmeyip, kalça ekleminde fonksiyonel iyileşmenin sağlandığı gözlenmiștir. Olgu no 12'de intramedullar pin uygulamasıyla gerçekleștirilen osteosentezin postoperatif radyolojik muayenesinde uygulanan pinin ucu kemik korteksini geçerek derialtında olduğu belirlenmiștir. Olguların uygulanan destekli bandajın etkisiyle, ilgili ekstremiteyi kullanımdaki olumsuzluk durumunu, daha sonra tolare ettikleri gözlenmiştir. Üçüncü hafta sonunda bandaj uzaklaştırılmıştır. 


\section{TARTIŞMA ve SONUÇ}

Arka ekstremite travmatik lezyonlarını oluşturan nedenler arasında trafik kazaları, bir yerde sıkıșma, hayvanların birbirleri ile olan kavgaları, kesici cisim ve ateşli silah yaralanmaları ile belirlenemeyen çeșitli nedenler sayılabilir (Swaim 1985). Hernon ve ark. (2018), kedilerle ilgili yaptıkları retrospektif çalışmada 185 travma olgusunun nedenlerini değerlendirmişler ve 104 trafik kazası (\%56.2), 49 bilinmeyen nedenler (\%26.5), 18 yüksekten düşme (\%9.7), 6 köpek saldırısı (\%3.2), 2 ateşli silah yaralanması (\%1.1), 2 küt travma (\%1.1), 2 kuyruktan çekilme (\%1.1), 1 at çifte darbesi $(\% 0.5)$ ve 1 de çarpma sonucu oluşan yaralanma $(\% 0.5)$ şeklinde rapor etmişlerdir. $\mathrm{Bu}$ olgulardan 116'sı çoklu travma yaralanmalarından etkilenirken 69'unun sadece bir travmatik etkiye maruz kaldığı belirtilmiştir. Literatür veride ilk sırada trafik kazası etken olarak belirtilmiş olup, çalışma olgularında ilk sırada yüksek düşme olmasıyla farklılık göstermiştir. Çalışmada sadece bir olguda trafik kazası etken olmuştur.

Ali (2013), tarafindan 5 ylllı (2005-2010) bir dönemde kedi ve köpeklerde gerçekleştirilen bir retrospektif çalışmada 650 olgudan 116'sında (\%17.8) kırık belirlenmiş, bunların \%67'si köpek ve \%23'ün kedi olduğu rapor edilmiştir. Kırıkla sonuçlanan travmaların çoğunluğunda köpeklerde trafik kazaları etken olurken, kedilerde yüksekten düşme etken olmuştur. Bu çalışmada değerlendirilen kedilerdeki 28 travmanın 10'u yüksekten düşme (\%35.7), 6'sı trafik kazası (\%21.4), 4'ü evde yaşanan bir travma (\%14.2), 4'ü hayvan ısırığı (\%14.2), 3'ü insan kaynaklı şiddet (\%10.7) ve 1'i de bilinmeyen bir neden (\%3.5) olarak aktarılmıștır. Çalıșma olgularında belirlenen travmatik nedenlerin dağılımında; 6 olgu'da yüksekten düşme (\%30), 6 olgu'da küt travma (\%30), 1 olgu'da trafik kazası (\%5), 1 olgu'da bir yerde sıkışma (\%5), 1 olgu'da sivri cisim kesiği (\%5) olurken 5 olgu'da (\%25) lezyonu oluşturan neden belirtilmemiştir. Bu dağllımda yüksekten düşme nedeninin ilk sırada oluşu ve oransal dağılımı literatür veri ile benzer olup, ayrıca aynı oranda küt travmanın eşlik etmesi literatür veriden farklılık göstermiștir.

Yaşam alanları ev olan, ancak dışarıya çıkmalarına izin verilen genç erkek kedilerde travmalara daha çok rastlandığı bildirilmiştir (Buffington 2002; Rochlitz 2003). Ancak Ali (2013) ve Senn ve ark. (2004) çalıșmalarında değerlendirilen travma geçmişi olan kedilerin çoğunluğunun dişi kediler olduğu belirtilmiştir. Çalışma olgularımızın cinsiyet dağılımı (\%55 dişi kediler) da Ali (2013) ve Senn ve ark. (2004)'nın litaraür verileri ile paralellik göstermektedir.

Ali (2013) ile Senn ve ark. (2004) çalışmalarında kliniğe getirilen olguların büyük çoğunluğunu genç hayvanların oluşturduğu ve yaş medyanını 30 aylık olarak hesaplandığı belirtilmiştir. Çalışma olgularının yaş dağılımı da benzer olduğu belirlenmiştir.

Travmatik nedenlerle oluşan lezyonların kısa sürede sağaltımı önemlidir (Selcer ve ark. 1987). Çalışma olgularındaki travmatik lezyonların endike olan sağaltım girişimleri en uygun zaman içinde gerçekleştirilmiş ve postoperatif süreye ilişkin herhangi bir olumsuzlukla karşılaşılmamıştır.

Kedilerde kırık şekillenmesinde ırk, cinsiyet ve yaş predispozisyonu bulunmamaktadır. Kırk oluşumundaki en çok rastlanan neden yüksekten düşmelerdir. Yaşam alanlarına göre trafik kazaları da etkendir (Fossum 2017). Çalışma olgularında kırık oluşturan başlıca nedenler de benzer özellikte olarak, yüksekten düșme ilk sırada olup aynı oranda küt travma da etken olurken, trafik kazası ancak bir olgu için etken olmuştur.

Kırığın sağaltımındaki amaç, fragmentlerin repozisyonunu ve fiksasyonunu gerçekleștirdikten sonra en kısa süreçte en ideal kaynama ile ekstremite fonksiyonunu tekrar kazandırmaktır. Ekstremite uzun kemiklerinin tranversal, spiral, oblik ve bazı parçalı kırık sağaltımında İM pin ile internal fiksasyon sağlanabilir (Fossum 2012; Sağlam ve ark. 1999). Çalışma olgularında endike olan intramedüller pin uygulamaları en kısa zamanda gerçekleştirilirken, postoperatif taşkın kallus gelişimi, açılı ya da yanlış kaynama oluşumu bulgularına rastlanılmamıştır.

Kedilerin eksizyon artroplastisini çok iyi tolere ettiği belirtilmiştir (İki ve Sağlam 2004). Eksizyon artroplastisi maliyeti düşük, başarı oranı yüksek olan bir sağaltım seçeneğidir (İki ve Sağlam 2004; Piermattei ve ark. 2006). Çalışmada olgu no 1'de caput femoris kırığı ve olgu no 2'de caput femoris luksasyonu sağaltımında endike olan eksizyon artroplastisi uygulanarak, fonksiyonel iyileşme sağlanmiştır.

Trochanter major'un avülsiyon kırıklarında Steinmann pin, Kirschner teli ve germe teli ile uyulamalarıyla fiksasyon gerçekleștirilir (Piermattei ve ark. 2006). Olgu no 7'de şekillenmiş olan trochanter major avülsiyon kırığında Steinmann pini ve germe teli kombinasyonu ile fiksasyon sağlandı.

Distal femur kırıklarında tek ya da çoklu intrameduller pin uygulaması, Rush pinleri, Kirschner telleri ile çapraz çivileme yöntemleri interkondiler kırıklarda da vidayla fragmentleri birbirine tutturma yöntemi önerilmektedir (Piermattei ve ark. 2006; Simpson ve Lewis 2003). Bu çalışmada suprakondiler femur kırığı belirlenen olgu no 8'de çapraz rush pini ve çapraz Kirschner teli uygulamasıyla kırığın fiksasyonu sağlandı. Olgu no11'de çapraz rush pini ve lag vidası uygulamasıyla suprakondiler ve intrakondiler kırığın fiksasyonu sağlandı.

Basit diyafizer tibia kırıkları intramedullar pin, plak, eksternal fiksatör, serklaj teli ve intramedullar pin uygulamalarıyla sağaltılabilir (Boudrieau 2003). İntramedullar pinle kombine edilerek çoklu serklaj uygulamaları, ekonomik yönden uygun olması yanında diyafizer spiral ve uzun oblik kırık sağaltımlarında başarılı sonuçlar alınmaktadır (Yardımcı ve Çetinkaya 2007; Montavon ve ark. 2009). Olgu no 12 ve 17 'deki tibia'nın diyafizer kırıklarında intramedullar pin uygulamasıyla kırığın fiksasyonu sağlandı. Olgu no 10 diyafizer kırığında intramedullar pin ve serklaj teli uygulamasıyla kırı̆̆ın fiksasyonu gerçekleştirildi.

Sonuç olarak, bu çalışmada, kedilerde karşılaşılan arka ekstremite travma lezyonlarının genel olarak tanımı, nedenleri, lokalizasyonu ve klinik olgular için endike olan sağaltım yöntemleri ve sonuçları ile uygulanan bu sağaltım girişimlerine ait detaylı bilgiler verilmiștir. Açık redüksiyon ve fiksasyon gerektiren lezyonların sağaltımı ile kırık olgularında başarılı sonuçlar alınmıştır. Olgularda kırıkların ağırlıklı olarak, femur ve tibia'da lokalize olduğu gözlendi. Luksasyon belirlenen olgu sayısı sınırlı olsa da, sağaltımlarındaki kapalı redüksiyon endikasyonu ile fonksiyonel iyileşme gerçekleştirildi. Çalışmanın klinik pratik uygulamalar için yönlendirici bir katkı sağlayacağı kanaatine varılmıştır.

Kedilerde karşılaşılan arka eksterimete lezyonlarının oluşum nedeni çoğunlukla yüksekten düşme ve küt travma gibi şiddetli travmalardır. Kedilerde arka ekstremite lezyonlarına oldukça sık rastlanmaktadır. Bu olgularda klinik, nörolojik ve radyolojik muayenelerinin dikkatli ve 
ayrıntılı bir șekilde yapılması gerekir. Travmatik bir etki direkt olarak etkilemiș olduğu yerde lezyon yaratırken, her olgunun olası diğer lezyonlar yönünden sistematik muayeneleri yapılırken, gerektiğinde ileri tanı yöntemleri de kullanılmalıdır. Kırıkların tipi, lokalizasyonu, deplasman durumu, hastanın mizacı göz önünde bulundurularak endike olduğuna karar verilen konservatif ya da operatif sağaltım yöntemi kısa zamanda gerçekleștirilmelidir. Deplasman bulunmayan kırıklarında destekli bandaj veya kısıtlı alan uygulamaları yeterli olabilir. Konservatif sağaltım uygulanan bu olgularda rutin bakım ve kontrol ișlemleri sürdürülmelidir. Ancak endike olduğu durumlarda operatif sağaltım tercih edilebilir.

\section{ÇIKAR ÇATIŞMASI}

Yazarlar, çıkar çatışması olmadığını beyan eder.

\section{YAZAR KATKILARI}

Fikir/Kavram: MS, HMT, AF

Tasarım: MS, HMT, AF

Denetleme/Danışmanlık: MS, HMT, AF

Veri Toplama ve/veya İșleme: MS, HMT, AF

Analiz ve/veya Yorum: MS, HMT, AF

Kaynak Taraması: MS, HMT, AF

Makalenin Yazımı: MS, HMT, AF

Eleștirel İnceleme: MS, HMT, AF

\section{KAYNAKLAR}

Ali LB (2013). Incidence, occurrence, classification and outcome of small animal fractures: a retrospective study (2005-2010). World Academy of Science, Engineering and Technology, International Journal of Biological, Biomolecular, Agricultural, Food and Biotechnological Engineering, 7 (3), 191-196.

Aslanbey D (2002). Veteriner Ortopedi ve Travmatoloji, Medisan Yayınevi, Ankara.

Boudrieau RJ (2003). Fractures of the radius and ulna. In: Textbook of Small Animal Surgery, Slatter D (Ed), 1953-1973, WB Saunders, Philadelphia.

Buffington CT (2002). External and internal influences on disease risk in cats. J Am Vet Med Assoc, 220 (7), 994-1002.

Fossum TW (2012). Small Animal Surgery. Mosby Inc. St. Louis.

Fossum TW (2017). Small Animal Surgery. Mosby Inc. St. Louis.

Harari J, Seguin B, Bebchuck T (1996). Closed repair of tibial and radial fractures with external skeletal fixation. Compendium on Continuing Education, 18, 651-64.
Hernon T, Gurney M, Gibson S (2018). A retrospective study of feline trauma patients admitted to a referral centre. J Small Anim Prac, 59 (4), 243-247.

İki Y, Sağlam M (2004). Köpeklerde caput ve collum femoris'in excision arthroplastisi. Veteriner Cerrahi Dergisi, 10 (1-2), 43-47.

Johnson AL, Dunning D (2005). Atlas of Orthopedic Surgical Procedures of the Dog and Cat. Elsevier Inc, St. Louis.

Kenneth J, Joceph D (2004). Handbook of Fractures. Lippincott Williams and Wilkins, USA.

Kolata RJ, Kraut NH, Johnston DE (1974). Patterns of trauma in urban dogs and cats: a study of 1000 cases. J Am Vet Med Assoc, 164(5), 499502.

Kolata RJ, Johnston DE (1975). Motor vehicle accident in urban dogs: a study of 600 cases. J Am Vet Med Assoc, 167 (10), 928-941.

Kolata RJ (1980). Trauma in dogs and cats: an overview. Vet Clin North Am Small Anim Prac, 10 (3), 515-522.

Montavon PM, Voss K, Langley-Hobbs SJ (2009). Feline Orthopedic Surgery and Musculoskeletal Disease. Saunders Elsevier, Philadelphia.

Piermattei DL, Flo GL (1997). Fractures of the femur and patella. In: Handbook of Small Animal Orthopedics and Fracture Repair. Brinker WO, Piermattei DL, Flo GL (Ed), 469-515, WB Saunders, Philadelphia.

Piermattei DL, Flo GL, Brinker Wo (2006). Handbook of Small Animal Orthopedics and Fracture Repair, W.B. Saunders Co, Philadelphia.

Rochlitz I (2003). Study of factors that may predispose domestic cats to road traffic accidents: part 1. Veterinary Record, 153 (18), 549-553.

Sağlam M, Kaya Ü (2000). Köpeklerde ön çapraz bağ kopmalarının sağaltımında modifiye intrakapsüler musculus tensor fasciae latae grefti uygulaması. Ankara Üniv Vet Fak Derg, 47(1), 81-88.

Sağlam M, Özba B, Kaya Ü, Bilgili H (1999). Köpeklerde femurun distal Salter Harris tip I ve tip II kırıklarının çapraz pin tekniği ile osteosentezi üzerine klinik çalışmalar. Veteriner Cerrahi Dergisi, 5 (34), 66-71.

Schebitz H, Kostlin R, Matis U, Brunnberg L (1983). Fractures of the jaw in dogs-fractures of the region of the pars incisiva mandibulae and the proc. Alveolaris ossis incisivi. Kleintierpraxis, 28, 285-290.

Scott HW, Mc Laughlin RM (2007). Feline Orthopedics. Manson, London.

Selcer BA, Buttrick M, Barstad R, Riedesel D (1987). The incidence of thoracic trauma in dogs with skelatal injury. J Small Anim Prac, 28(1), 21-27.

Senn NA, Gadallah SM, Zabady MK (2004). Studies on somebone disorders in cats: incidence, radiological assessment and surgical management. J Egypt Vet Med Assoc, 64(3), 113-137.

Simpson DJ, Lewis DD (2003). Fractures of the femur In: Textbook of Small Animal Surgery, Slatter D (Ed), 2059-2089, WB Saunders, Philadelphia.

Slatter D (2003). Textbook of Small Animal Surgery. Elsevier, Philedelphia.

Swaim SF (1985). Management and bandaging of soft tissue injuries of dog and cat feet. J Am Anim Hosp Assoc, 21 (3), 329-340.

UsAK (2004). ErișimAdresi, www.medicine.ankara.edu.tr/surgical_medical /turkish/kadro/kurs.html Erişim Tarihi: 21/09/2004.

Yardımcı C, Çetinkaya MA (2007). Kedilerde diyafizer segmental ve parçalı femur kırıklarının intramedullar pin ve serklaj kombinasyonuyla sağaltımı: 17 olgu. Ankara Üniv Vet Fak Derg, 54 (1), 11-16. 